\title{
Vincent's Angina in a 17-Year Old Girl With Emotional Stress: A Case Report
}

\author{
Farzad Khademi ${ }^{1}$; Ehsan Aryan ${ }^{1, *}$ \\ ${ }^{1}$ Antimicrobial Resistance Research Center, Department of Medical Bacteriology and Virology, Qaem University Hospital, School of Medicine, Mashhad University of Medical \\ Sciences, Mashhad, IR Iran \\ ${ }^{*}$ Corresponding author: Ehsan Aryan, Antimicrobial Resistance Research Center, Department of Medical Bacteriology and Virology, Qaem University Hospital, School of Medicine, \\ Mashhad University of Medical Sciences, Mashhad, IR Iran. Tel: +98-5138453019, E-mail: ehsanaryan@hotmail.com
}

Received: September 4, 2014; Revised: June 24, 2015; Accepted: July 1, 2015

\begin{abstract}
Introduction: Vincent's angina refers to acute necrotizing ulcerative lesions of the oral mucosal membranes and tonsils.
Case Presentation: In this case, we report a 17-year old girl with emotional stress referred with symptoms of Vincent's angina. Gram staining showed numerous fusospirochetal bacteria. With antibiotic therapy, amoxicillin and cephalexin, no clinical improvement was observed but improvement was achieved by using mouthwash and salt water.

Conclusions: It seems that there is a close relationship between stress and the Vincent angina disease. Moreover, simple diagnostic and therapeutic procedures such as Gram staining and using mouthwash and salt water are beneficial in case of Vincent angina.
\end{abstract}

Keywords: Gingivitis, Necrotizing Ulcerative; Stress; Psychological; Case Reports

\section{Introduction}

Vincent's angina is a life-threatening and mildly contagious infection of the oral mucosal membranes. This infection is also known as trench mouth, Acute Necrotizing Ulcerative Gingivitis (ANUG), fusospirochetal gingivitis, Vincent's stomatitis and Vincent infection (1-4). There were numerous reports of this infection during the world wars (3). The disease was first described by Plaut in 1894 and Vincent in 1896 cited in Barnes et al. (1). Spirochetes, fusiform bacteria and species of bacteroides are the most frequently organisms isolated from the lesions of the patients (5). It is frequently seen in young adults but may also affect children during their first dentition (3) and poor oral hygiene, smoking, emotional stress, alcohol consumption and malnutrition have mentioned as the predisposing etiologic factors for this disease (6). The disease forms a red and irregular ulcerated area on the tonsils and their surrounding mucosal membranes, having a rather firm base filled with loose necrotic tissue (pseudomembrane) (3). Despite passing a century from the study of etiology, pathogenesis and treatment of this disease, many issues remain unclear about it (6). Several studies have suggested different methods for treating the disease such as using broad-spectrum antimicrobial agents (6). The purpose of this case report is to recommend mental and emotional stress as a more prominent factor in development of the Vincent's angina disease.

\section{Case Presentation}

In this report, we present a case of a 17-year old girl referred to laboratory of microbiology in Qaem University Hospital, Mashhad, northeast of Iran, in February 2014. She complained of sore throat, cervical lymphadenopathy and halitosis. The patient had no fever. The oral cavity, nose, nasopharynx and larynx were clear but had a gray pseudomembrane and ulcer without bleeding on her tonsils.

At first, the disease was clinically diagnosed as a viral infection of upper respiratory tract by a physician. Sampling was performed from tonsil tract lesions for Gram staining. In Gram-stained throat smear, fusospirochetal bacteria were observed (Figure 1). Antibiotics such as amoxicillin and cephalexin were administered for this patient for seven days at first, but no clinical improvement was observed. However, recovery was achieved at the third week of the disease with drug discontinuation and using mouthwash and salt water. Presence or absence of Vincent's angina symptoms is mentioned in Table 1 . Also, Table 2 shows predisposing factors of the disease.

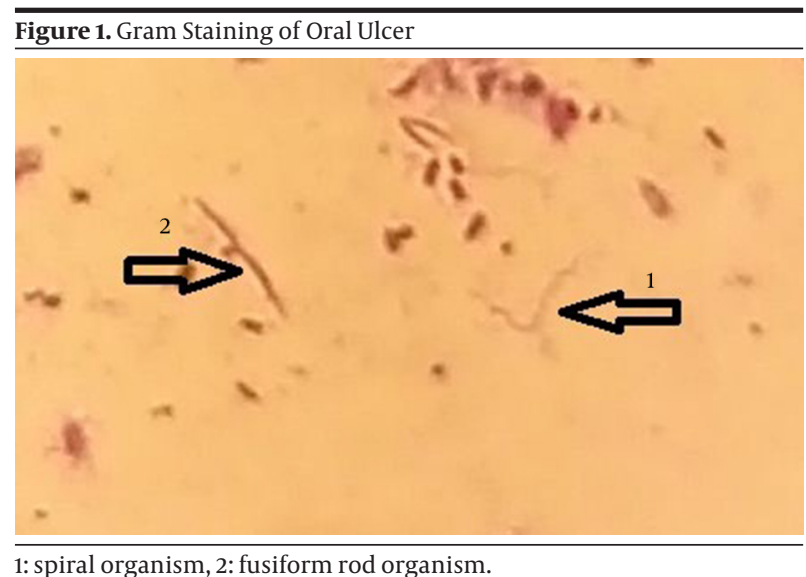

Copyright (C) 2015, Infectious Diseases and Tropical Medicine Research Center. This is an open-access article distributed under the terms of the Creative Commons Attribution-NonCommercial 4.0 International License (http://creativecommons.org/licenses/by-nc/4.0/) which permits copy and redistribute the material just in noncommercial usages, provided the original work is properly cited. 
Table 1. Symptoms of the Disease in the Patient

\begin{tabular}{lc}
\hline Symptoms & Presence/Absence $^{\mathrm{a}}$ \\
\hline $\begin{array}{l}\text { Inflammation of oropharyngeal } \\
\text { mucous membrane }\end{array}$ & + \\
Redness and bleeding & - \\
\hline Tonsillitis & + \\
Mild to severe pain & + \\
\hline Tonsil ulcer & + \\
Halitosis & + \\
\hline Anorexia & + \\
\hline Fatigue & + \\
\hline Fever & - \\
\hline
\end{tabular}

a (+): positive, (-): negative.

Table 2. Evaluation of Predisposing Factors in Index Case

\begin{tabular}{lc}
\hline Risk Factors & Presence/Absence $^{\mathrm{a}}$ \\
\hline Allergy to foods or medicines & + \\
\hline Smoking & - \\
\hline Poor oral hygiene & - \\
\hline Artificial teeth & + \\
\hline Emotional stress & + \\
\hline Anxiety & - \\
\hline Jagged teeth & - \\
\hline Radiotherapy and chemotherapy & - \\
\hline $\begin{array}{l}\text { Alcohol consumption } \\
\text { Consumption of hot foods and } \\
\text { spices }\end{array}$ & - \\
\hline Sensitivity to mouthwashes & - \\
\hline Lipstick usage & \\
\hline $\begin{array}{l}\text { Occupational exposure to dyes } \\
\text { and heavy metals }\end{array}$ & - \\
\hline a (+): positive, (-): negative. & - \\
\hline
\end{tabular}

\section{Discussion}

Vincent's angina refers to acute necrotizing ulcerative infections of the oral mucosal membranes with bleeding, halitosis and inflammation of the tonsils. The disease is considered as mixed anaerobic infection and pathogenic organisms are probably normal flora of the mouth that for unknown reasons can be causing the disease (6). Vincent's angina is fairly contagious among children and its transmission depends upon close contact. Recently, studies have been reported some cases of death from Vincent's angina. Therefore, it seems to be important to investigate the affecting factors in incidence of the disease (7). Studies show that host factors such as stress, smoking and poor oral hygiene involved in this disease. The patients complain of throat sore, halitosis and tonsil ulcer. Regional lymphadenopathy is variable and fever is not common (4). In this patient, stress, tonsil ulcer, halitosis and throat pain were observed. There was no fever and poor oral hygiene. Interestingly, it seems that stress has an important role in development of disease in this case report. Before onset of the disease, she was in the condition of severe emotional and mental stress (the death of her father).

The diagnosis on the basis of clinical symptoms can be problematic, because the disease might be confused with viral infections, diphtheria, syphilis and a group A betahemolytic streptococcal infection $(3,4)$. Therefore, for the purpose of differentiating, pseudo-membranous and ulcerative angina should be studied in the laboratory.

In these cases, the diagnosis should be confirmed by Gram-staining and direct microscopic examination for fusospirochetal bacteria observation (8). In our case report, the disease was mistakenly diagnosed as viral infection by physician but it was detected in laboratory of microbiology as Vincent's angina using Gram staining and microscopic examination.

For the treatment of Vincent's angina, the use of antibiotics and chemical agents has been suggested. Oral penicillin is one of the most important antibiotics that suggested for the treatment of these mixed anaerobic infections. When penicillin cannot be used, other antibiotics include: tetracycline, erythromycin and metronidazole have been recommended $(4,6)$. However, in our case the patient was consumed amoxicillin and cephalexin for seven days but she did not respond to treatment. Finally, recovery was achieved at the third week of the disease with drug discontinuation and using mouthwash and salt water. It seems that simple therapeutic procedures such as mouthwash and salt water are beneficial in case of Vincent's angina.

\section{Acknowledgements}

The authors are grateful to Mahmoud Bagheri and Parvaneh Bagherinia, the staff of microbiology laboratory in Qaem university hospital, Mashhad, IR Iran for their sincerely cooperation.

\section{Authors' Contributions}

Farzad Khademi in collecting data and writing of the article and Ehsan Aryan in diagnosis of the disease and article revision were participated.

\section{References}

1. Barnes GP, Bowles W3, Carter HG. Acute necrotizing ulcerative gingivitis: a survey of 218 cases. J Periodontol. 1973;44(1):35-42.

2. Biswas D, Stafford N. Borrelia tonsillitis: common symptoms but uncommon organism. Eur Arch Otorhinolaryngol. 2010; 267(6):989-90.

3. Cummings GO. Vincent's Angina. New Engl J Med. 1930; 202(16):768-71. 


\section{Khademi F et al.}

4. Kaplan D. Acute necrotizing ulcerative tonsillitis and gingivitis (Vincent's infections). Ann Emerg Med. 1981;10(11):593-5.

5. Loesche WJ, Syed SA, Laughon BE, Stoll J. The bacteriology of acute necrotizing ulcerative gingivitis. J Periodontol. 1982;53(4):223-30.

6. Hartnett AC, Shiloah J. The treatment of acute necrotizing ulcer- ative gingivitis. Quintessence Int. 1991;22(2):95-100.

7. King JM. Vincent's Angina, with Report of a Case. Cal State J Med. 1918;16(7):334-6.

8. MacFarlane TW, Ross CA, Cohen BJ. Letter: Oral ulceration and infective agents. Br Med J. 1974;1(5908):643. 